\title{
Nonoperative Care Including Rehabilitation Should Be Considered and Clearly Defined Prior to Elective Orthopaedic Surgery to Maximize Optimal Outcomes
}

\author{
Daniel I. Rhon, P.T., D.Sc., Ph.D., and Christopher J. Tucker, M.D.
}

\begin{abstract}
Orthopaedic surgery has revolutionized the expectations for restoration of physical function after musculoskeletal injury and, along with physical therapy, has transformed the limits of recovery. Many orthopaedic procedures have a high success rate for improving quality of life and patient-reported outcomes, yet these procedures carry some level of risk, including postoperative complications. The stepped-care model of health care delivery, when applied to musculoskeletal care, recommends implementing less-intense and lower-risk treatments with known efficacy, such as promotion and education of self-management strategies and physical therapy, before more-invasive and higher-risk treatments such as surgery. This model of managing musculoskeletal disability can improve efficiency of care delivery and reduce medical costs at the health system level. Unfortunately, there is a documented lack of implementing an appropriate course of conservative care, especially physical therapy, prior to surgery across multiple orthopaedic disciplines including sports, spine, and trauma medicine and joint arthroplasty. Failure to respond to nonsurgical treatment has been suggested as a requisite component of the surgical appropriateness criteria, yet practical application can be elusive. Multiple barriers to adequate utilization of conservative treatment exist, including U.S. payment models that increase out-of-pocket expense for patients, negative patient perception of therapy, unreasonable patient expectations from therapy versus surgery, and communication barriers between patient, surgeon, and therapist. Surgeons should ensure that high-quality guidelineappropriate care is delivered early and adequately to their patients. Rehabilitation professionals have a responsibility to deliver high-value care, properly documenting the type and extent of treatment to improve surgical decision-making between surgeons and patients. Criteria to determine appropriateness for surgery should include a standardized and extensive assessment of failed therapies prior to certain elective surgeries. Improved collaboration between surgeons and rehabilitation professionals can result in improved outcomes for patients with musculoskeletal disorders. Level of Evidence: $V$, expert opinion
\end{abstract}

S urgical procedures have revolutionized expectations for physical form and function after

From the Department of Rehabilitation Medicine, Brooke Army Medical Center, San Antonio, Texas, U.S.A. (D.I.R.); the Department of Rehabilitation Medicine, The Uniformed Services University of Health Science, Bethesda, Maryland, U.S.A. (D.I.R.); the Department of Orthopaedics, Walter Reed National Military Medical Center, Bethesda, Maryland, U.S.A. (C.J.T.); the Department of Surgery, The Uniformed Services University of Health Sciences, Bethesda, Maryland, U.S.A. (C.J.T.).

The authors report that they have no conflicts of interest in the authorship and publication of this article. Full ICMJE author disclosure forms are available for this article online, as supplementary material.

Address correspondence to Daniel Rhon, Primary Care Musculoskeletal Research, Department of Rehabilitation Medicine, Brooke Army Medical Center, 3551 Roger Brooke Dr, JBSA Fort Sam Houston, TX 78234, U.S.A. E-mail:daniel.i.rhon.ctr@mail.mil

(C) 2021 THE AUTHORS. Published by Elsevier Inc. on behalf of the Arthroscopy Association of North America. This is an open access article under the CC BY-NC-ND license (http://creativecommons.org/licenses/by-nc-nd/4.0/). 2666-061X/211097

https://doi.org/10.1016/j.asmr.2021.09.038 orthopaedic injury, and advances in surgical procedures have transformed the limits of recovery. For example, surgical management for certain fractures can reduce nonunion and malunion rates and return individuals to work or sport more quickly. ${ }^{1}$ Distal radius fractures and displaced and intra-articular calcaneus fractures appear to have significantly better outcomes when managed surgically. ${ }^{2}$ Complex injuries such as comminuted or open fractures can be stabilized efficiently with surgical fixation techniques, in many cases with increased function versus healing without intervention.

For other injuries, especially nontraumatic or less acute injuries, surgery is also a potential treatment option. For example, carpal tunnel decompression and total knee arthroplasty can be very effective and appears to result in better outcomes compared with nonsurgical treatment, and arthroscopic knee surgeries (anterior cruciate ligament [ACL] reconstruction and meniscus repair) can be effective in certain subgroups. ${ }^{3}$ 
However, surgical interventions come with some risk of harm and the possibility of adverse events. For example, even though total knee arthroplasty results in substantial improvement in quality of life and function for most individuals, it still poses risk for adverse events and complications not present with nonsurgical care. ${ }^{4,5}$ ACL reconstruction affords some athletes the opportunity to return to sport $(\leq 70 \%$ have been shown to return to high-level sport ${ }^{6}$ ); however, studies have reported that $\leq 1$ in 5 athletes can reinjure their $\mathrm{ACL},{ }^{7}$ with even higher rates of $\leq 1$ in 4 athletes if they are age $<25$ years. ${ }^{8}$ Although less common, other potential postoperative complications can occur including infection, loss of joint motion, and long-term strength deficits. ${ }^{9,10}$ Complications and adverse events are ubiquitous within the field of orthopaedic surgery, with varying incidence and severity. Because of these potential risks, and the fact that there are many evidence-based nonsurgical treatment options that lead to successful recovery, surgeons should entertain a trial of lower-risk, nonsurgical treatments when feasible, before consideration of surgical options.

\section{Stepped-Care Models of Health Care Delivery for Managing Orthopaedic Injuries}

Stepped-care delivery was initially defined in the mental health and psychiatric fields of medicine. ${ }^{11,12}$ The goal was to use the most effective, yet least resource-intensive, treatment as the initial option for most patients, and then transition (i.e., step up) to more specialized and intensive care only for those who failed to respond with lower tiers of care. The term has subsequently been used for the management of some musculoskeletal pain conditions, specifically low back pain. ${ }^{13,14}$ Less-intense and lower-risk treatments with known efficacy (self-management guidance to stay active and positive, nonopioid analgesics, etc.) are used first, reserving more intense interventions (opioids, epidural injections, surgical procedures) for those who fail to respond to initial care.

These models for managing musculoskeletal pain improve efficiency of care and reduce medical costs at the health system level. ${ }^{15}$ Many clinical guidelines and best-care recommendations endorse a stepped-care approach for managing musculoskeletal disorders, namely to offer high-quality nonsurgical care prior to surgery. ${ }^{16,17}$ In scenarios where high-quality evidence and clinical practice guidelines consider physical therapy and surgical repair to be equally appropriate and effective, such as with the American Academy of Orthopaedic Surgeons guidelines for managing rotator cuff tears ${ }^{18}$ or nonobstructive meniscus tears, ${ }^{19}$ the recommendation is to start with conservative management, which is less costly and carries lower risk for complications. Surgery in place of physical therapy for some conditions has even been defined as "low-value" care. $^{20}$

\section{Using Failure to Respond to Nonsurgical Treatment as Part of Surgical Appropriateness Criteria}

Although stepped-care guidelines for pain management recommend a trial of nonsurgical management (which is more conservative) prior to surgery, how often this occurs in practice is less known. Peters and colleagues conducted a systematic review of the literature to determine a consensus for reported surgical criteria for femoroacetabular impingement (FAI) syndrome. $^{21}$ The authors found that only $44 \%$ of all studies reported that previously failed conservative treatment was a requirement for surgery. In another cohort of 1870 individuals undergoing hip arthroscopy for FAI syndrome, only $40.9 \%$ of patients had physical therapy in the year prior to surgery. ${ }^{22}$ Of those that did have physical therapy, the median number of rehabilitation visits by each individual was 2 , and only $11.8 \%$ of the cohort attended $\geq 6$ visits of rehabilitation prior to surgery. This is in light of evidence suggesting that 6 visits is likely the lowest conservative limit of what might be considered an appropriate dose to expect any effect from exercise therapy. ${ }^{23}$

The lack of prescribing physical therapy prior to surgery is also seen within other orthopaedic subspecialties. In a cohort of 411 patients undergoing elective spine surgery, only $34.8 \%$ received any physical therapy in the year prior, and only $14.6 \%$ had $\geq 6$ sessions of rehabilitation. ${ }^{24}$ In an epidemiological assessment of 11 million patients undergoing knee arthroplasty in the United States, only $10 \%$ of all patients were referred to physical therapy at any point in the 5 years prior to surgery. ${ }^{25}$ An assessment of claims data over a 2-year period for patients undergoing hip or knee arthroplasty found that only $10.5 \%$ of all patients $(\mathrm{n}=4733)$ had any physical therapy prior to surgery. ${ }^{26}$ In another cohort of 88,985 patients with musculoskeletal disorders, only $29.3 \%$ were referred to physical therapy in the first 90 days after the initial diagnosis, and this delay in seeing a physical therapist was associated with a greater risk for receiving opioids. ${ }^{27}$ Finally, Khoja et al. ${ }^{28}$ assessed 2.4 million knee osteoarthritisrelated visits between 2007 and 2015, finding a 50\% reduction in referrals to physical therapy placed by orthopaedic surgeons during that time frame. Referral rates to physical therapy from primary care providers were unchanged during the period but were much lower than those of orthopaedic surgeons. Rates of referrals to physical therapy equated to $<5 \%$ for primary care and $9 \%$ to $15 \%$ for orthopaedic surgeons. ${ }^{28}$ Overall, it seems there is room for improvement of stepped-care options for many musculoskeletal 
conditions that end up being treated surgically. Should a proper regimen of nonsurgical care be a prerequisite for determining the appropriateness of elective surgical procedures?

\section{Practical Reasons That Adequate Nonsurgical Care May Be Dismissed Prior to Surgery}

Identifying reasons for inadequate utilization of conservative management prior to surgery may not be as straightforward as one might suspect. The reasons likely reflect the often-complicated and sometimes discordant nature of health care delivery, which involves multiple medical disciplines and potentially complicated payment models. In the United States, reimbursement models have been changing, requiring greater out-ofpocket costs for patients to attend physical therapy, ${ }^{29}$ and higher out-of-pocket expenses are associated with reduced physical therapy visits. ${ }^{30}$ Opioids are much cheaper for patients, which may be why they are prescribed more often than physical therapy. ${ }^{27}$

Patient perception and expectation can be a factor, with some patients convinced that nothing other than surgery can adequately address their problem, causing reluctance to try other treatments such as physical therapy. A qualitative assessment of patient beliefs prior to knee arthroplasty revealed erroneous beliefs about the disease process: that their knee was "bone on bone" or caused by "wear and tear," and that joint vulnerability would only be exacerbated by exercise and physical activity. ${ }^{31}$ These potentially harmful beliefs can preclude progress and effective care delivery, especially since exercise and physical activity are core recommendations in most guidelines for the management of knee osteoarthritis ${ }^{17,32}$ and considered front-line treatment, ${ }^{33}$ and there is no evidence to indicate they should be avoided, even in cases with severe joint degeneration. ${ }^{34}$ Many patients have doubts about the effect of exercise as a treatment, ${ }^{35}$ especially when they've been given a pathobiological diagnosis. The diagnostic label used by the surgeon itself can influence a patient's perception of the need for surgery, as seen in the treatment for rotator cuff injuries, ${ }^{36}$ and can influence whether the patient is even willing to try or avoids any other treatments. ${ }^{37}$

Patient expectations are powerful prognostic variables $^{38}$ for both surgical ${ }^{39,40}$ and nonsurgical ${ }^{41}$ care. A $^{2}$ large meta-analysis found low to moderate association between patient expectations about surgery outcomes and quality of life scores after surgery. ${ }^{40}$ Surgeons can improve the value of care by helping set realistic expectations for both surgical and nonsurgical care. ${ }^{42}$ Finally, there is the potential for patients to be referred to physical therapy and have it consist of lowvalue care. Reimbursement models tied to high-value physical therapy treatments have been discussed ${ }^{29}$ and could address this problem. Along those lines, and in some scenarios, a supervised course of physical therapy is not always superior to a single session focused on self-management advice and guidance, ${ }^{43}$ or even a self-directed internet-based exercise program. ${ }^{44}$

\section{Recommendations for Future Practice and Research}

We provide recommendations for improving steppedcare for musculoskeletal disorders, relevant to 3 different stakeholders (Table 1).

\section{Rehabilitation Specialists}

Clinicians providing nonsurgical care for patients should focus on interventions supported by the best evidence and with the potential for greatest impact. ${ }^{16}$ Even when patients were referred to see physical therapists prior to surgery, $<50 \%$ of patients in some settings received exercise therapy, and even fewer $(<12 \%)$ participated in what could be considered a minimal effective dose of $\geq 6$ sessions. ${ }^{22,24}$ High-value treatment options are imperative, ${ }^{45}$ which also includes appropriate dosing of the intervention. Dosing can influence the magnitude of the treatment effect size and should always be considered when evaluating a proper course of nonsurgical care, with greater intensity often associated with better outcomes. ${ }^{46-48}$ However, more does not always mean better. ${ }^{49}$ In short, the goals should be to maximize effectiveness of treatment so that the need for surgical intervention is either postponed or eliminated entirely. Documentation should be adequate to allow a surgeon to easily understand that the patient was offered an appropriate regimen of the best nonsurgical care available, should the need arise to determine the appropriateness and timing of surgery.

\section{Surgeons}

Surgeons should examine the content of prior nonsurgical care to ensure that the poor response to treatment was based on a best-evidence regimen of care that would reasonably elicit any improvement if it were possible. They should encourage high-value care from the physical therapists to whom they refer patients. Although adequate dosing is context and condition specific, anything short of 10 visits or $<6$ weeks - the bare minimum threshold for exercise therapy-is likely not enough to result in meaningful physiological and therapeutic change. ${ }^{46,50-52}$ Caution is warranted in relying on a patient's recollection of treatment details, as a dichotomous yes or no answer to whether they have had "physical therapy" may not be enough to consider the adequacy of nonsurgical care.

When initially referring patients to physical therapy for a trial of conservative care, the surgeon plays a critical role in setting the patient's expectations for the 
Table 1. Summary of recommendations to improve use of adequate nonsurgical treatment before elective orthopaedic surgery procedures

\begin{tabular}{|c|c|c|}
\hline Rehabilitation Specialists & Surgeons & Researchers \\
\hline $\begin{array}{l}\text { - } \text { Ensure adequate regimen of } \\
\text { nonsurgical care (appropriate } \\
\text { frequency, duration, and intensity) }\end{array}$ & $\begin{array}{l}\text { Examine content of nonsurgical care } \\
\text { to confirm that dose was proper for } \\
\text { therapeutic effect }\end{array}$ & $\begin{array}{l}\text { - In surgical trials, report type and } \\
\text { details of nonsurgical care received by } \\
\text { all participants leading up to surgery } \\
\text { (could be part of criteria for entry into } \\
\text { study or simply provided descriptively } \\
\text { for all) }\end{array}$ \\
\hline $\begin{array}{l}\text { - Adequately document dosing } \\
\text { information (including total visits for } \\
\text { each type of treatment) so that } \\
\text { surgeons can better interpret } \\
\text { adequacy of treatment before } \\
\text { determining appropriateness of } \\
\text { surgical interventions }\end{array}$ & $\begin{array}{l}\text { - Set patient expectations about the } \\
\text { value of nonsurgical care with proper } \\
\text { education and use of empowering } \\
\text { language (surgeon is likely to have the } \\
\text { greatest influence of any clinician on } \\
\text { patient's beliefs, expectations, and } \\
\text { choice of treatment) }\end{array}$ & $\begin{array}{l}\text { - Continue to address gaps in } \\
\text { knowledge about barriers to } \\
\text { completing adequate nonsurgical care } \\
\text { (driven by patients, clinicians, and/or } \\
\text { health systems and payers) }\end{array}$ \\
\hline
\end{tabular}

potential effectiveness of the nonsurgical care. In 1 survey, $71 \%$ of patients reported that the physician recommendation was their primary influence in determining appropriateness of treatment options. ${ }^{53} \mathrm{In}$ turn, patient expectations are associated with quality of life after surgery. ${ }^{40}$ Even the use of common terms such as "failure" and "conservative" has been criticized because the terms can bias patients toward surgical interventions. ${ }^{54}$ For example, "failing" nonsurgical care can imply that surgical care is then where "success" can ultimately be achieved. It conveys that nonsurgical care is just a step on the normal trajectory toward surgery. ${ }^{54}$ When nonsurgical care is labeled "conservative," the meaning is not clear for patients and can implicitly suggest that surgical alternatives somehow are bolder-and therefore more powerful or adequate. ${ }^{54}$ For these reasons, recommendations have been made to just use plain labels of "surgical" or "nonsurgical" care. ${ }^{54}$ Patient adherence with treatment can be improved simply with quality communication skills on the part of the physician. ${ }^{55}$ The diagnostic label alone can influence a patient toward or away from a surgical procedure, ${ }^{37}$ including how the results of radiology reports are portrayed to the patient. ${ }^{56}$

\section{Researchers}

The quality of evidence in published studies surrounding the appropriateness of surgical interventions could be improved if studies tracked and reported the type and extent of non-urgical care received prior to surgery. This information has the potential to help explain variations in treatment-effect size seen with surgical interventions. Presurgical variables are often predictors of success after surgery. ${ }^{57,58}$ There could be significant heterogeneity in subgroup patient phenotypes who have exhausted all forms of nonsurgical care compared with those who have not had any of this care or have had low-quality care. These factors could help explain the difference between responders and nonresponders after surgery. We recommend that future orthopaedic surgery trials report the type and extent of nonsurgical treatments each study participant has received prior to surgery to better understand the types of patients participating in trials and the study outcomes, as well as to allow for adequate comparison of treatments, including physical therapy, across studies. Adequate nonsurgical care is context and condition specific $^{59}$ but includes both the actual intervention and its corresponding dose. Therefore, establishing a specific number of visits to meet appropriateness criteria is likely too simplistic and outside the scope of this paper.

\section{Summary}

In summary, surgeons and rehabilitation professionals can work together to improve outcomes for patients with musculoskeletal disorders. Surgeons should ensure that high-quality, guideline-appropriate care is delivered early and adequately to patients. Rehabilitation professionals have a responsibility to deliver high-value care and properly document the type and extent of treatment to improve decision-making between surgeons and patients. Criteria to determine appropriateness for surgery should include a standardized and extensive assessment of tried and failed therapies that took place prior to certain elective surgeries. Improved collaboration between surgeons and rehabilitation professionals will result in improved outcomes for patients with musculoskeletal disorders.

\section{Acknowledgments}

Time for this effort was supported in part by the Uniformed Services University, Department of Physical Medicine \& Rehabilitation, Musculoskeletal Injury Rehabilitation Research for Operational Readiness (MIRROR) (HU00011920011). The views expressed herein are those of the authors and do not necessarily reflect the official policy or position of Brooke Army Medical Center, Walter Reed National Military Medical Center, the U.S. Army Office of the Surgeon General, the Department of the Army, the Defense Health 
Agency, the Department of Defense, the Uniformed Services University, nor the U.S. Government.

\section{References}

1. Smeeing DPJ, van der Ven DJC, Hietbrink F, et al. Surgical versus nonsurgical treatment for midshaft clavicle fractures in patients aged 16 years and older: A systematic review, meta-analysis, and comparison of randomized controlled trials and observational studies. Am J Sports Med 2017;45:1937-1945.

2. Skou ST, Juhl CB, Hare KB, Lohmander LS, Roos EM. Surgical or non-surgical treatment of traumatic skeletal fractures in adults: Systematic review and meta-analysis of benefits and harms. Syst Rev 2020;9:179.

3. Blom AW, Donovan RL, Beswick AD, Whitehouse MR, Kunutsor SK. Common elective orthopaedic procedures and their clinical effectiveness: Umbrella review of level 1 evidence374:n1511.

4. Skou ST, Roos EM, Laursen MB, et al. A randomized, controlled trial of total knee replacement. $N$ Engl J Med 2015;373:1597-1606.

5. Lu N, Misra D, Neogi T, Choi HK, Zhang Y. Total joint arthroplasty and the risk of myocardial infarction: A general population, propensity score-matched cohort study. Arthritis Rheumatol 2015;67:2771-2779.

6. Brophy RH, Schmitz L, Wright RW, et al. Return to play and future ACL injury risk after ACL reconstruction in soccer athletes from the Multicenter Orthopaedic Outcomes Network (MOON) group. Am J Sports Med 2012;40: 2517-2522.

7. Barber-Westin S, Noyes FR. One in 5 athletes sustain reinjury upon return to high-risk sports after ACL reconstruction: A systematic review in 1239 athletes younger than 20 years. Sports Health 2020;12:587-597.

8. Wiggins AJ, Grandhi RK, Schneider DK, Stanfield D, Webster KE, Myer GD. Risk of secondary injury in younger athletes after anterior cruciate ligament reconstruction: A systematic review and meta-analysis. Am J Sports Med 2016;44:1861-1876.

9. Eckenrode BJ, Carey JL, Sennett BJ, Zgonis MH. Prevention and management of post-operative complications following ACL reconstruction. Curr Rev Musculoskelet Med 2017;10:315-321.

10. Gobbi A, Karnatzikos G, Chaurasia S, Abhishek M, Bulgherhoni E, Lane J. Postoperative infection after anterior cruciate ligament reconstruction. Sports Health 2016;8:187-189.

11. Katon W, Von Korff M, Lin E, et al. Stepped collaborative care for primary care patients with persistent symptoms of depression: A randomized trial. Arch Gen Psychiatry 1999;56:1109-1115.

12. van Straten A, Hill J, Richards DA, Cuijpers P. Stepped care treatment delivery for depression: A systematic review and meta-analysis. Psychol Med 2015;45:231-246.

13. Maher C, Underwood M, Buchbinder R. Non-specific low back pain. Lancet 2017;389:736-747.

14. Von Korff M, Moore JC. Stepped care for back pain: Activating approaches for primary care. Ann Intern Med 2001;134:911-917 (9 Pt 2).
15. Garcia AN, Cook CE, Rhon DI. Adherence to stepped care for management of musculoskeletal knee pain leads to lower health care utilization, costs, and recurrence. Am J Med 2021;134:351-360.el.

16. Lin I, Wiles L, Waller R, et al. What does best practice care for musculoskeletal pain look like? Eleven consistent recommendations from high-quality clinical practice guidelines: Systematic review. Br J Sports Med 2020;54:79-86.

17. Kolasinski SL, Neogi T, Hochberg MC, et al. 2019 American College of Rheumatology/Arthritis Foundation Guideline for the Management of Osteoarthritis of the Hand, Hip, and Knee. Arthritis Care Res 2020;72:220-233.

18. Weber S, Chahal J. Management of rotator cuff injuries. J Am Acad Orthop Surg 2020;28:e193-e201.

19. van de Graaf VA, Noorduyn JCA, Willigenburg NW, et al. Effect of early surgery vs physical therapy on knee function among patients with nonobstructive meniscal tears: The ESCAPE randomized clinical trial. JAMA 2018;320: 1328-1337.

20. Schwartz AL, Landon BE, Elshaug AG, Chernew ME, McWilliams JM. Measuring low-value care in Medicare. JAMA Intern Med 2014;174:1067-1076.

21. Reiman MP, Peters S, Sylvain J, Hagymasi S, Ayeni OR. Prevalence and consistency in surgical outcome reporting for femoroacetabular impingement syndrome: A scoping review. Arthroscopy 2018;34:1319-1328.e9.

22. Young JL, Wright AA, Rhon DI. Nonoperative management prior to hip arthroscopy for femoroacetabular impingement syndrome: An investigation into the utilization and content of physical therapy. J Orthop Sports Phys Ther 2019;49:593-600.

23. Kemp JL, King MG, Barton C, et al. Is exercise therapy for femoroacetabular impingement in or out of FASHIoN? We need to talk about current best practice for the nonsurgical management of FAI syndrome. Br J Sports Med 2019;53:1204-1205.

24. Carrignan JA, Simmet RT, Coddington M, et al. Are exercise and physical therapy common forms of conservative management in the year before lumbar spine surgery? Arch Phys Med Rehabil 2020;101:1389-1395.

25. Dhawan A, Mather RC 3rd, Karas V, et al. An epidemiologic analysis of clinical practice guidelines for nonarthroplasty treatment of osteoarthritis of the knee. Arthroscopy 2014;30:65-71.

26. Snow R, Granata J, Ruhil AVS, Vogel K, McShane M, Wasielewski R. Associations between preoperative physical therapy and post-acute care utilization patterns and cost in total joint replacement. J Bone Joint Surg Am 2014;96:e165.

27. George SZ, Goode AP. Physical therapy and opioid use for musculoskeletal pain management: Competitors or companions? Pain Rep 2020;5:e827.

28. Khoja SS, Almeida GJ, Freburger JK. Recommendation rates for physical therapy, lifestyle counseling, and pain medications for managing knee osteoarthritis in ambulatory care settings: A cross-sectional analysis of the National Ambulatory Care Survey (2007-2015). Arthritis Care Res 2020;72:184-192.

29. Carvalho E, Bettger JP, Goode AP. Insurance coverage, costs, and barriers to care for outpatient musculoskeletal therapy and rehabilitation services. N C Med J 2017;78:312-314. 
30. Dolot J, Hyland M, Shi Q, Kim H-Y, Viola D, Hoekstra C. Factors impacting physical therapy utilization for patients with nonspecific low back pain: Retrospective analysis of a clinical data set. Phys Ther 2020;100:1502-1515.

31. Bunzli S, O'Brien P, Ayton D, et al. Misconceptions and the Acceptance of Evidence-based Nonsurgical Interventions for Knee Osteoarthritis. A Qualitative Study. Clin Orthop Relat Res 2019;477:1975-1983.

32. Bannuru RR, Osani MC, Vaysbrot EE, et al. OARSI guidelines for the non-surgical management of knee, hip, and polyarticular osteoarthritis. Osteoarthritis Cartilage 2019;27:1578-1589.

33. Susko AM, Fitzgerald GK. The pain-relieving qualities of exercise in knee osteoarthritis. Open Access Rheumatol 2013;5:81-91.

34. Bosomworth NJ. Exercise and knee osteoarthritis: Benefit or hazard? Can Fam Physician 2009;55:871-878.

35. Thorstensson CA, Roos EM, Petersson IF, Arvidsson B. How do middle-aged patients conceive exercise as a form of treatment for knee osteoarthritis? Disabil Rehabil 2006;28:51-59.

36. Zadro JR, O'Keeffe M, Ferreira GE, et al. Diagnostic labels for rotator cuff disease can increase people's perceived need for shoulder surgery: An online randomized controlled experiment. J Orthop Sports Phys Ther 2021;51:401-411.

37. Nickel B, Barratt A, Copp T, Moynihan R, McCaffery K. Words do matter: A systematic review on how different terminology for the same condition influences management preferences. BMJ Open 2017;7:e014129.

38. Laferton JAC, Kube T, Salzmann S, Auer CJ, SheddenMora MC. Patients' expectations regarding medical treatment: A critical review of concepts and their assessment. Front Psychol 2017;8:233.

39. Rossi MJ, Brand JC, Provencher MT, Lubowitz JH. The expectation game: Patient comprehension is a determinant of outcome. Arthroscopy 2015;31:2283-2284.

40. Auer CJ, Glombiewski JA, Doering BK, et al. Patients' expectations predict surgery outcomes: A meta-analysis. Int J Behav Med 2016;23:49-62.

41. Cormier S, Lavigne GL, Choinière M, Rainville P. Expectations predict chronic pain treatment outcomes. Pain 2016;157:329-338.

42. Rossi MJ, Lubowitz JH, Brand JC, Provencher MT. Making the right treatment decision requires consideration of utility and reconsideration of value. Arthroscopy 2017;33: 239-24l.

43. Hopewell S, Keene DJ, Marian IR, et al. Progressive exercise compared with best practice advice, with or without corticosteroid injection, for the treatment of patients with rotator cuff disorders (GRASP): A multicentre, pragmatic, $2 \times 2$ factorial, randomised controlled trial. Lancet 2021;398:416-428.

44. Allen KD, Arbeeva L, Callahan LF, et al. Physical therapy vs internet-based exercise training for patients with knee osteoarthritis: Results of a randomized controlled trial. Osteoarthritis Cartilage 2018;26:383-396.
45. Cook CE, Denninger T, Lewis J, Diener I, Thigpen C. Providing value-based care as a physiotherapist. Arch Physiother 2021;11:12.

46. Young JL, Rhon DI, Cleland JA, Snodgrass SJ. The influence of exercise dosing on outcomes in patients with knee disorders: A systematic review. J Orthop Sports Phys Ther 2018;48:146-161.

47. Young JL, Rhon DI, de Zoete RMJ, Cleland JA, Snodgrass SJ. The influence of dosing on effect size of exercise therapy for musculoskeletal foot and ankle disorders: A systematic review. Braz J Phys Ther 2018;22: 20-32.

48. Gallois M, Davergne T, Ledinot P, Ravaud P, Regnaux J-P. Dosage of preventive or therapeutic exercise interventions: Review of published randomized controlled trials and survey of authors. Arch Phys Med Rehabil 2017;98:2558-2565.e10.

49. Clewley D, Iftikhar Y, Horn ME, Rhon DI. Do the number of visits and the cost of musculoskeletal care improve outcomes? More may not be better. J Orthop Sports Phys Ther 2020;50:642-648.

50. Vina J, Sanchis-Gomar F, Martinez-Bello V, GomezCabrera MC. Exercise acts as a drug; the pharmacological benefits of exercise. Br J Pharmacol 2012;167: $1-12$.

51. Østerås B, Østerås H, Torstensen TA, Vasseljen O. Doseresponse effects of medical exercise therapy in patients with patellofemoral pain syndrome: A randomised controlled clinical trial. Physiotherapy 2013;99:126-131.

52. Herold F, Müller P, Gronwald T, Müller NG. Doseresponse matters! A perspective on the exercise prescription in exercise-cognition research. Front Psychol 2019;10: 2338.

53. Boye GN, Murray K, Clohisy JC, Kim Y-J. Feasibility of a randomized clinical trial for treatment of femoroacetabular impingement of the hip. Orthop J Sports Med 2015;3:2325967115592844.

54. Ring DC, Dobbs MB, Gioe TJ, Manner PA, Leopold SS. Editorial: How the words we use affect the care we deliver. Clin Orthop Relat Res 2016;474:2079-2080.

55. Zolnierek KBH, Dimatteo MR. Physician communication and patient adherence to treatment: A meta-analysis. Med Care 2009; 47:826-834.

56. Rosenkrantz AB. Differences in perceptions among radiologists, referring physicians, and patients regarding language for incidental findings reporting. Am J Roentgenol 2017;208:140-143.

57. Raman J, Walton D, MacDermid JC, Athwal GS. Predictors of outcomes after rotator cuff repair-A metaanalysis. J Hand Ther 2017;30:276-292.

58. Judge A, Arden NK, Cooper C, et al. Predictors of outcomes of total knee replacement surgery. Rheumatology 2012;51:1804-1813.

59. Brody LT. Effective therapeutic exercise prescription: The right exercise at the right dose. J Hand Ther 2012;25: 220-231. 